\title{
City Ascending, City Imploding
}

I.

One by one, we filed back into a rickety van. Days of travel over smooth highways and potholed lanes, narrated in hours of conversation, song, laughter, and silence, had fostered the distinctive familiarity that sometimes develops with time shared in transit. A few days into the journey, we'd fallen into territorial patterns: by will or by default, we'd claimed and repeatedly reoccupied a specific seat in the van. Sliding into my place, I joined in a collective, exhausted exhale. Our energy was spent; our senses were full.

From the early morning hours, our group of thirteen architects and professors had been touring the headquarters, and then several building sites, of the Bangalore property development firm called Biodiversity Conservation India (Ltd.). We'd covered the firm's philosophical basis for environmental design, learned a set of technical strategies for achieving building efficiency and maximizing environmental performance, and, then, finally, we walked several construction sites to experience some BCIL projects in the making.

The van revved its engine, filling the air with the sour sweetness of exhaust. Tired but still curious, I thumbed through the day's collection of brochures, pamphlets, and fliers. Settling on a BCIL brochure for potential clients, I skimmed the introductory pages. "DON'T JUST BUY A HOME, BUY INTO A CAUSE," urged its opening page, the text laid out in capital letters over a large green exclamation point. "This is the future of urban living," it continued, "Welcome aboard."

My eyes raced over descriptions of the many residential projects that were planned or underway at BCIL. We'd walked several of those project sites over the course of the day, and I'd found each more impressive, innovative, and surprising 


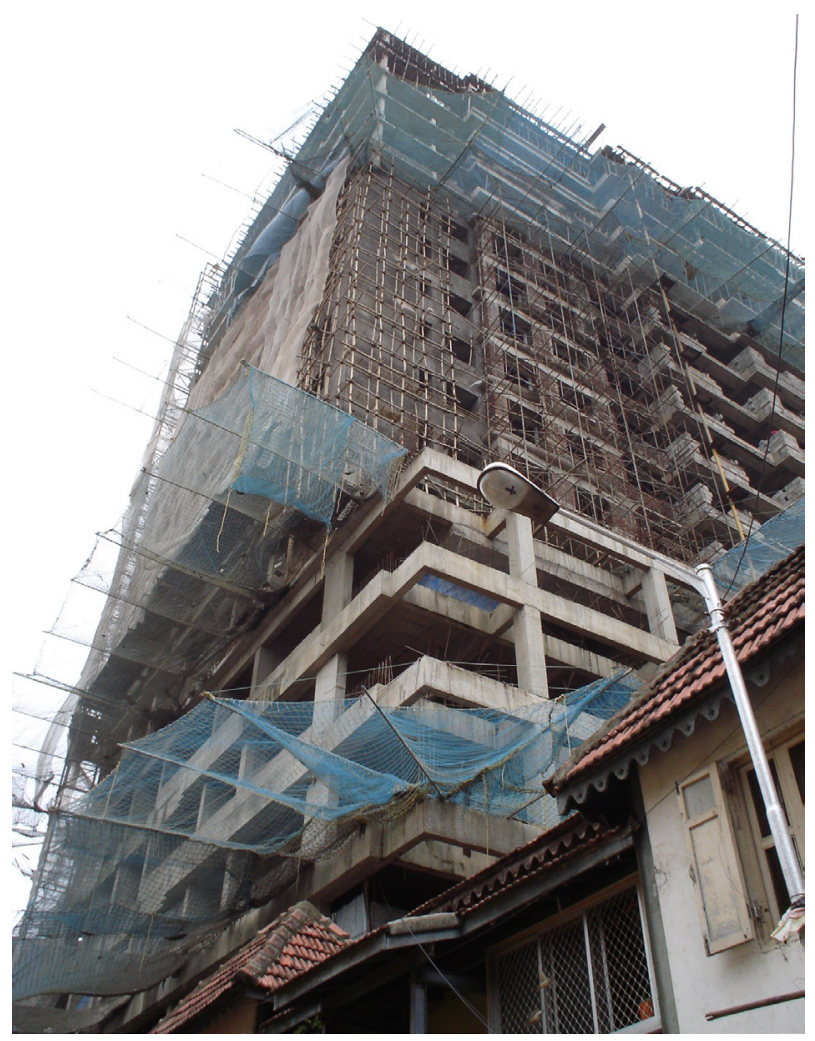

FIGURE 1. Construction in Mumbai, 2012. Photo by the author.

than the last. The architects I traveled among-all practicing professionals who had returned to graduate school to enroll in a master's degree program in environmental architecture-were noticeably inspired; each site seemed to present something new to marvel at. The residential developments bridged the ideas we'd spoken of at our orientation at BCIL headquarters and the things, the buildings, the ideas rendered in material form-or, at least, the things in the midst of becoming material form.

My attention switched from the brochures to an announcement delivered from the front of the van, where the Head of Rachana Sansad Institute of Environmental Architecture, Roshni Udyavar Yehuda, stood balanced precariously against the sway and bounce of an uneven dirt road. "There is one more stop," she declared, "and it will include lunch!" Exhaustion gave way to excitement and relief; we were ready to eat.

Closing the brochure in my lap, I paused for a moment over its concluding text: 
BCIL. If you haven't heard of us before, that's alright. We like it that way. Because we believe that some of the most revolutionary ideas in the world have quiet, unknown beginnings. BCIL is all about tomorrow's thinking today. The very fact that you're reading this page is important; it tells us you're thinking on the same lines. It tells us you are exactly the kind of person we're looking for: the kind that looks ahead, sees all the angles, and sees holistic understanding. Our emphasis on community and conservation is not an alternative. It is an imperative for the future.

With that, the van pulled to a dust-choked stop. Renewed by the thought of lunch, we filed out into the searing sun, following Yehuda as she guided us to a small building that appeared to be a private residence. A small sign read, "Alternative Technology Foundation"; the group's founder greeted us warmly at the door.

Our plates soon heavy with dal and rice, we settled on scattered cushions to eat and chat. After a few minutes, our host offered a more formal greeting, followed by a short lecture about the work of the ATF. As his talk came to a close, its tone grew urgent. He said:

People like us—architects and designers committed to green design—see the future. Common people do not; my neighbor does not. The future is our responsibility. We are like soldiers of sustainability. You are all like soldiers of sustainability.

This was a day like many others in the Rachana Sansad Institute of Environmental Architecture, a day spent seeking to learn about environmental, or "green," design from encounters with specific examples. In the classroom and on field trips such as this one, we sought the philosophical basis for what we studied, a kind of architecture that was very new, and yet distinctly ancient, all at once. We sought demonstrations of its material possibility and the technical strategies that made it plausible. Most importantly, however, it was a day of reinforcing the idea that, left on their present trajectory, India's cities would suffer severe social and environmental crises. Eventually, conditions would become so extreme that a new vanguard of urban professionals who could navigate the terrain of sustainability-let us call them green experts-would be needed to lead those cities to remedy, and to a salvaged future.

The "soldiers of sustainability" I studied among were but one part of this essential vanguard, yet they regarded their work as central to its mission. In the near future, their capacity to think in an integrated way, and to imagine and design future built forms that would embody BCIL's "holistic understanding," would be nothing short of essential; the same propensity to "look ahead" and "see all the angles" could eventually form the very basis for human urban survival.

Perhaps most importantly, tomorrow's environmental architects were cultivating a shared sense of belonging to and being among this vanguard. Our sense of good and right design was cultivated together in the context of our training; it left us with a shared moral ecology foundational to the salvaging of the future cityindeed, to the salvaging of the very future itself. ${ }^{1}$ 
The long day behind us, and our appetites now quiet, we returned to the van for the last segment of the day's journey. We rode in near-silence, soon crossing onto smooth pavement that seemed to lull each head to sleep. I clutched again my stack of BCIL brochures, mindful of the day's crossings of past, present, and future. Recalling the words spoken at ATF, my mind echoed with phrases, "people like us" and "seeing the future." In the span of a day and a daylong journey, the architects I traveled and studied among were a step closer to joining the vanguard of a multivalent, global social movement called urban sustainability.

II.

As if to satirize twentieth century categories that located Mumbai in the "developing" world, a highly visible, citywide advertising campaign for the real estate development firm India Bulls proclaimed India Bulls: Consider it Developed. I first encountered this slogan in 2007, a time when Mumbai was alive with construction. Across the city, large, flimsy walls marked the temporary boundaries between the city standing and the city under construction. Behind the barriers rose the hidden components of the future city, sunk in vast pits that secured their foundations. From the roadside, one could only rehearse the omnipresent slogan: Consider it Developed.

A layered, massive mosaic of urban material and social life, Mumbai in that period was palpably transforming in real time. Optimism reigned in amplified public spheres alive with celebratory spectacles, media coverage, and forecasts of seemingly endless economic growth. The city was emboldened in large measure by India's relative insulation from an otherwise debilitating global financial recession; it seemed positioned to pronounce its place at the nerve center of an undeniably ascendant Asia. Such a place meant little on the global economic landscape if not that India, and its financial hub, Mumbai, were unquestionably "developed."

Yet the Mumbai of that particular present was also mired in almost iconic poverty; the city's buildingscape was famously dominated by slum housing, and transected by notoriously substandard transportation, electricity, and water delivery infrastructure. ${ }^{2}$ In that moment, Mumbai was a complex historical product of colonial spatial production, often-opaque and brutal politics, and sometimes spectacular scandal, each driven as much by bureaucratic authority and corporate power as by India's oft-referenced status as the world's largest democracy.3.4

Globally prevalent mappings of urbanization, in which Mumbai regularly figured as a major location on a "planet of slums," circulated as they did, but the city nevertheless rode a wave of growth, however asymmetrical, through which developers and government officials promised a Mumbai yet to come., "Consider it developed" conveyed more than the enormous capacity for growth and change that the building industry celebrated in its everyday construction spectacles; it also captured a defiant postcolonial confidence. Mumbai was a city whose time had come, emblematic of a euphoric Indian century. At least, perhaps, the slogan 
allowed one to revel in that possibility. Consider it developed, because in the twenty-first century this is not only reasonable, it is also wise. It would be difficult to dispute that the city was a good investment. ${ }^{7}$

International reports and government ministries outlined an Indian future animated by dizzying rates of change. As the National Planning Commission called for an almost seven percent increase in energy production to keep up with projections of nine percent growth, the consulting firm McKinsey Global Institute predicted an astonishing expansion of Mumbai's built landscape. ${ }^{8}$ The city's commercial built-up area alone, it claimed, would grow from 2.9 billion square feet in 2005 to 20 billion square feet by $2030 . .^{9}$ Just a few years later, in 2014, the global real estate firm Cushman \& Wakefield reported that net office space across eight major Indian cities had increased by sixteen percent in the first half of the year, compared to the same period the previous year. ${ }^{10}$ This was to say nothing of the residential and housing sectors, in which growth and transformation drove countless policy studies and notoriously lucrative speculative markets. ${ }^{11}$

Beyond the vexing socioeconomic challenge of the present, then, stood the shining promise of growth. Those who could participate in that growth enjoyed tremendous power and watched their personal wealth multiply. In this context, developers, builders, and financiers enjoyed a special status. But equally important, if not always as powerful, were certain urban planners, architects, and urban policy professionals, who, in visible if not always overtly powerful ways, voiced reminders that the city faced environmental challenges as well. They sometimes championed, and sometimes contested, official pronouncements about the appropriate path to the Mumbai in the making.

If the grueling poverty and vulnerability that characterized city life for most Mumbaikars could in some ways be assuaged by euphoric narratives of economic growth, the city's biophysical future was that hope's undoing. Studies of the present and possible effects of environmental degradation, frequent and erratic major storm events, loss of coastal land to sea level rise, possibly catastrophic flooding, and, ironically, sub-continental water scarcity all punctuated predictions for the city's future ecological reality. ${ }^{12}$ Mumbai's energy and food security scenarios, its water budget, air quality, and vulnerability to storms would all reshape the biophysical stage for the city's unfolding. ${ }^{13} \mathrm{New}$ and sometimes massive populations of migrants were expected to mobilize in response to coastal conditions and sea level changes across South Asia; this would rework the human landscape as it reshaped the urban interface between the city and the sea. ${ }^{14}$

Dire poverty and future environmental stresses thus held the promise of growth in uncertain suspension: the idealized key would be to grow in a way that maximized ecological vitality as well as economic profits, and that effected more equitable distribution of a vast array of socioenvironmental benefits. To achieve this, a particularly "green" expertise was essential: one that could guide the form of the new city toward environmental and social adaptability. ${ }^{15}$ 
III.

In February of 2012, on a first walk through the middle class residential neighborhood that would be my fieldwork home that year, I spotted a newsstand display hung with the attention-nabbing covers of the day's latest papers and magazines. The week's issue of Time Out Mumbai was on prominent display, beckoning its readers with an enormous headline: "Imagine Mumbai." Intrigued by the premise, and by the cover image of a pleasant, tree-lined coastal urban promenade, I bought the issue and tucked it among my things. Later, working my way through the magazine's articles and images, I paused over the many examples of a supposedly possible future version of Mumbai. This Mumbai was laden with lush urban landscapes woven of leafy parks, diverse open spaces devoted to leisure, and vegetated zones devoted to the unique ecology of a healthier, more climate-resilient coastline. Each example was at once profoundly unfamiliar, and yet-or so the convincing renderings suggested-profoundly possible for those who dared to "imagine Mumbai."

The portal to this barely recognizable city-communicated in this form to a small, elite, and relatively young readership_-based its declaration of timeliness and possibility on the particular bureaucratic moment. According to formalized urban planning cycles, Mumbai had ostensibly - though not exactly in practicecreated a new urban development plan in twenty-year intervals. Since 1966, the Maharashtra Region and Town Planning Act, established in that year, required every municipal corporation to prepare and implement city development plans. Calls to an elite young readership to Imagine Mumbai echoed the task of professional urban planning publics as they debated the appropriate form and content of the current urban plan's successor. In this sense, the future plan for Mumbai could be treated as an open question, ripe for certain publics to reimagine. ${ }^{16}$

By this time, the official plan-making process was already controversial, in part because a consortium that included French consulting firms had been appointed to write the new plan. ${ }^{17}$ In part as a response, prominent calls for public participation (and spectacles that sought to enable it) created a sense among a specific subset of elite and professional Mumbaikars that their individual and collective acts of "imagining Mumbai" mattered, and moreover, that they could and should be galvanized to influence the form and content of the new urban plan.

Broadly ecological sensibilities dominated the public meetings and exhibitions through which these publics sought to influence the plan's form. The idea of "open space," a category encompassing calls for more recreational and leisure space, concerns about public health and well-being, and a host of ecological conservation objectives, came to capture and convey a complex of potential remedies for the spatial and environmental deficiencies of the present and the biophysical challenges that climate change ensured. In this sense, calls to integrate urban sustainability concerns into the new development plan assumed the form of a civic 
imperative. ${ }^{18}$ To promote the conditions needed to constitute a fuller, more ideal Mumbai was to promote an attendant biophysical and material form.

The political issue of how, precisely, to ensure that an amended development plan would be both formulated and operationalized, however, was usually tucked into subtext. This had the effect of foregrounding the planners, architects, and other urban professionals who imagined, narrated, and justified it rather than the political economic structures, bureaucracies, and circumstances that enabled or prevented them. The urgency of the moment, emboldened by the looming plan deadline but already evident in intensifying concern over the risks to coastal cities posed by climate change, seemed to excuse the discursive circumvention of the political mechanics of actual change. Mumbai's complex and famously problematic bureaucratic, corporate, and development apparatus would have to be reformed, but precisely how was muted, if even present, in calls to bring urban sustainability into the new plan. ${ }^{19}$

But back in the pages of the bourgeois print media voice of Time Out Mumbai, a young, elite, English-speaking readership was nevertheless called on to take responsibility for the Mumbai of tomorrow. The most effective way to do that, it suggested, was through design thinking. "How would you redesign the city?" one article asked, suggesting an enticing combination of agentive power and civic duty. Each piece proposed a different strategy or focal Mumbai geography, but all converged on a single point: "open spaces." Vegetated, accessible public areas designed with a combination of trees, gardens, and leisure in mind, were a primary tool for achieving a more desirable city, according to this logic.

To "imagine" Mumbai in this context was thus an invitation to rethink its socioecological destiny, its spatial configuration, and the patterns that came together in the process of urban development. It was also a confident gesture that seemed to imply that such rethinking could itself have real, material consequences. The exercise was a first step that, if mobilized in design arenas that could spark unspecified collective civic agency, might change the spatial course of Mumbai's future. Placing the work of transforming imagination into action in the hands of urban professionals, then, bestowed a sense that they could have an influence-or at least a voice-in ensuring Mumbai's very survival.

The historical moment was clear and indisputably urgent. True ecological and economic vitality were still possible for Mumbai, but the opening signaled by the development plan was finite and pressing. It was in this moment, in this complex and dynamic city, that I embarked on an ethnographic journey among architects seeking training in green design.

In this book, I take special interest in the training, thinking, and voices of a particular group of Mumbai-based architects. Theoretically, architects were among the urban professionals potentially poised to envision, convey, and create a material 
bridge between the city's present built landscape and the environmental, material, and social city still to come. Architects were among those working to design and actualize the estimated 2.3 billion square meters of floor space that would, in fewer than two decades, rise across India. ${ }^{20}$ In Mumbai, a subset of architects aspired to do this in a way sensitive to the altered energy, water, and environmental vulnerability profile of the entire subcontinent, while trying to also address the deep socioeconomic asymmetries that demanded change. ${ }^{21}$ Like architects and planners from many points across history and place, their design aspirations sometimes linked to imagining new social worlds that might accompany their blueprints for India's new built landscape..$^{22}$ Their puzzle was not simply the form of buildings to design, but how particular design approaches and techniques might help to cultivate more desirable relationships between people, material life, and the urban environment.

In some ways, the architects I describe in this book- "green," or environmental architects-engaged in a practice of hope: hope that the urban future could be ecologically and socially reformed, and hope that their profession would position them in a way to enact that reform. At its surface, their endeavors might evoke ideas like those suggested by David Harvey, for example, in his Spaces of Hope. In it, Harvey directly addresses the theoretical figure of the architect to invite us to consider the social worlds that could inhabit the spaces architects imagine, and to invigorate the suggestive possibility of the utopian landscapes of which those sociospatial worlds are a part.

In this theoretical guise, however, the architect is often ascribed some degree of agentive power; we look to the imaginative sphere it signals as the source of new shapes for human history itself. Echoing this Marxian sensibility may leave the reader inclined to regard the architect's connection to built, material forms as automatically powerful, not only for imagining new social worlds, but also for distinguishing the human social world from nonhuman nature. ${ }^{23}$ Yet, as this work will show, the engaged social world of environmental architecture is always and automatically suspended in a web of socionatural power relations, bureaucratic structures, and historical legacies that not only shape the architect's agentive potential, but the very imaginary itself. The work among environmental architects that I recount in this book aims to show how a set of social agents simultaneously composed important new visions of a more desirable Mumbai, and experienced structural limits to their capacity to forge from those visions the city of the present. ${ }^{24}$

In a lived reality of resilient and unequal power relations, in a city in which the material development of the urban form proceeds according to far more powerful actors than most urban design professionals, what compelled Mumbai-based architects to seek environmental training? What motivated them to enroll in a degree program that required significant commitments of time, money, and intellectual energy, but returned only scarcely discernable leverage to make change? 
To these central puzzles, this book offers insight into the contemporary power of conceptions of the future, showing how shared notions of temporality emerge as critical for understanding the reproduction of environmental actions in the present. While a wide range of theorists have issued calls to take temporality seriously, and authors like Appadurai have persuasively established the place of the future as a "cultural fact", it is only through sustained attention to the everyday life of ecology in practice-here, as environmental architecture training and work-that we can come to appreciate the multidimensional role of temporality as it animates social structure and social agency. ${ }^{25,26,27}$ My aim in this ethnography is to better understand and compose an architectural figure, as well as a contextualized actor, who is firmly embedded in the social structures and power relations of the present, and yet compelled by a specific and powerful set of temporal sensibilities to expect, and react to, a dramatically different anticipated future. ${ }^{28}$

I thus attend to the cautiously confident, deeply aspirational politics that took shape among a group of environmental architects in a Mumbai on the cusp of a new urban development plan. As I will describe, theirs was a politics of expectation and possibility that sought to defy both the triumphant pronouncements of Mumbai as a "development" mission accomplished, and repeated declarations that enduring inequality and intensifying environmental vulnerability sealed for the city a chaotic urban fate. I focus on a social arena of relative, but always compromised, privilege in which actors are neither fully empowered elites nor fully dispossessed. Unsatisfied with Mumbai's political economy and its environment, the architects I describe organized their aspirations to change both according to an emergent moral logic - a moral ecology that, as I will show, relied on the inevitabilities of the environmental future to reposition their active potential and to remake urban socioecological life.

Separating social life in the city from the biophysical vitality of the environment has long been untenable, so such separations are inconsistent with the lived social reality of the environmental architects profiled here. Across social theory and studies of social and cultural change, rejecting the modern human/nature divide has opened myriad theoretical and conceptual approaches to nature, and has helped us rethink our understanding of social change. Invoking ideas like "species being," 29 "more than human geographies,"30 or "multi-species ethnography,"31 we are roundly challenged across disciplines and analytical postures to reconsider the intersectional arenas previously designated as humans here, in the city, and nature beyond-there, in the hinterlands. Marx's classical line between the bees and the architects no longer holds solid sway, bringing nature "back in" to political economic analytics and humans into old categories of nature. Indeed, as Dipesh Chakrabarty has argued, bringing nonhuman nature "back in" is no longer a discipline-based choice, ${ }^{32}$ and conceptualizing agency exclusively in the human sphere is nearly impossible to sustain. ${ }^{33}$

At the same time, "urban nature" has gained new and globally circulating traction as a useful, and indeed often essential, conceptual component of the twenty-first 
century city. ${ }^{34}$ Urban environments and their futures, concerns often referenced in shorthand through terms like sustainability and resilience, ${ }^{35}$ are undeniably central features of cities as they unfold. Urban professionals who mediate this domain thus emerge as particularly needed, desired, and powerful actors on a stage of expertise emboldened by its claim to ensure and safeguard sustainability.

Or do they? The puzzle at the center of this book is one of coupled environmental and political transformation. Our lens is a collective of architects, brought together by a shared experience of formal training, and rendered a resilient, selfidentified community of activist-professional-practitioners in the aftermath of that experience. They speak in this book of their passion for a practice that will eventually align social and environmental vitality, and they assemble key concepts in interaction and fellowship with one another and with the author, the anthropologist. The sphere of praxis they share merges a particular version of urban ecosystem ecology knowledge with design techniques, creating a science-design driven, shared point of reference that they repeatedly indexed as "good design." The book's later focus on the realm of post-training, lived professional practice allows us to trace a conceptual and experiential bridge between the work of the imaginary and the work of politics. Across the book, I draw from ethnographic data and analysis to better understand the relative power of architects as social actors who seek to integrate training and practice. What emerges, I will show, is a specific and important form of green expertise, but one that remains a vocation in waiting.

Despite the formidable social structures that condition their capacity to act in the present, I will describe how architects were nevertheless key agents of urban socioecological transformation in a city more often noted for its seemingly intractable unsustainability than for its demonstration that a different, more ecologically vital urban world is possible. Crucially, they remain agents in waiting: the configuration of bureaucratic power, urban development, and capital that composes Mumbai's political landscape ultimately suspends "good design" in a future still to come. ${ }^{36}$

\section{GREENING THE URBAN REVOLUTION}

Green architecture and design are expansive, conceptually and in practice. The terms invoke other equally broad concepts, including urban ecology, sustainability, ${ }^{37}$ and urban nature. Like many malleable and oft-employed terms-globalization, modernity, and culture among them-green architecture and environmental design must be anchored to lived social life if we are to discern their form and meaning. In this study, that understanding is derived from the training and social world I encountered at The Rachana Sansad Institute for Environmental Architecture in Mumbai.

For analytical grounding, I employ an "ecologies of urbanism" approach, drawing from previous theoretical work with K. Sivaramakrishnan and the insights of 
the many colleagues who have been a part of our Ecologies of Urbanism in Asia projects. ${ }^{38}$ This approach builds on formative thinking across several arenas of scholarship to propose studies of urban nature-making that foreground place and context. Rather than assuming a singular, universal ecology, and thus a unified experience of urban nature, our intention is to identify the multiple forms of nature-in biophysical, cultural, and political terms - that have discernable impact on power relations and human social action. In Ecologies of Urbanism in India, we wrote:

Identifying and understanding these multiple forms is central to the analytic. Some hinge on human social processes, and some on non-human and/or biophysical ones. Each intersection may involve competing worldviews, aspirations, imaginaries, and assessments of the stakes of urban environmental change. Social efforts to ensure, create, or imagine ecological stability that characterize these intersections are often infused with ideas of political, social, or cultural improvement, revival, or restoration. To promote particular urban ecological futures, then, may also involve the reproduction or contestation of cultural ideas of belonging to certain social groups, territories (including the city, the nation-state, the region, and the realm called the 'global'), or, indeed, nature itself. ${ }^{39}$

At the same time, an analytical stance that is exclusively social is only partial, and quite unhelpful for the reasons discussed above. The ecologies of urbanism approach therefore demands attention to the underlying biophysical conditions and natural histories of a place, and it requires a multi-scalar perspective that varies its analytical parameters according to the social and/or biophysical processes under consideration. The result, as we write, may be for example that "the appropriate boundaries of 'the city' are not automatically known from municipal borders or demographic concentrations. Likewise, nation-state borders (may) not determine where and how a study begins and ends." ${ }^{\circ}$ Our focus is thus on processes, and the imperative of tracing the scales and boundaries that the processes themselves compose. In this sense, the very connections that allowed my own ethnographic work to move from Kathmandu to Mumbai, discussed in the preface, extend from the idea of ecologies of urbanism.

While the analytic has proven generative in our efforts to understand urban environmental change in Asia, we recognize the enduring centrality of the biophysical sciences, which usually lay claim to the term "ecology" in its singular form. The biophysical sciences may offer only one in a constellation of competing and meaningful understandings of urban nature, and while each may enjoy a privileged or empowered social position at different moments, there is no question that regarding scientific ways of knowing biogeochemical processes and systems as unimportant leaves us with little capacity to understand socioenvironmental change. In this study, then, I pay particular attention to the specific concepts, methods and imperatives from ecosystem ecology that the architects assembled in 
order to compose a scientific basis for "good design." I ask what kind of ecological science the environmental architects learned. How did they employ that knowledge in their environmental design approaches?

This question is motivated, in part, by the many ways that environmental scholars across disciplines have sought to more fully integrate ecosystem science and social studies of the environment. A subfield of ecosystem ecology, the biophysical science of urban ecosystem ecology tends to follow theoretical and methodological innovations in ecology that include chaos theory, disturbance ecology, patch dynamics, and efforts to understand spatial heterogeneity. Urban ecology is not a science of fully fixed successional patterns, homeostasis, human "disturbance," and wholly predictive modeling that social analysts have historically, at times with significant consequences, assumed. ${ }^{41}$

In North America, two urban research sites among the US National Science Foundation's Long Term Ecosystem Research (LTER) initiatives have been particularly generative of urban ecology research findings and analyses. ${ }^{42}$ These centers have long forged new ground in the scientific theory of urban ecosystems, and they have made significant contributions to the analytical tools available to scientists, social researchers, and design practitioners. An exemplary recent volume that captures some of the interdisciplinary accomplishments of this work, and its innovative models for urban ecosystems, is Pickett, Cadenasso, and McGrath's Resilience in Ecology and Urban Design: Linking Theory and Practice for Sustainable Cities, ${ }^{43}$ but the wealth of particular and integrative studies produced in the Phoenix and Baltimore LTER's, as well as the many other ecosystem-science grounded urban ecology research consortia in North America and beyond, is vast indeed. ${ }^{44}$ For the purpose of this project, I wish to note the longstanding efforts among ecosystem scientists to understand human social dynamics, and to meaningfully include them in their conceptual and research models. ${ }^{45}$ Attempts to bridge natural scientific understandings of the way nonhuman nature works and understandings of how human societies work are neither new nor exclusive to urban ecology, ${ }^{46}$ yet fully understanding how social and biophysical structures, functions, and agents mutually produce one another remains a complex and robust challenge.

What is striking to scholars in the environmental social sciences and humanities is the extent to which the science of urban ecosystem ecology has made it imperative to integrate human communities and human action into conceptual and practical models, not as automatic "disturbances," but as "natural" components. ${ }^{47}$ Similarly, a notable aspect of many so-called green or environmental design interventions is the aspiration to integrate a sophisticated understanding of biogeochemical cycles, energy flows, and other landscape considerations into architectural thinking and decision-making. ${ }^{48}$ Both worldwide and in specific locales, various sets of largely standardized metrics have emerged for assessing the degree to which individual buildings are attributed more formalized and quantifiable "green" status (e.g., LEED or BREEAM standards), but in an epistemological 
and practical sense, as will be explored in this book, environmental architecture transcends mere building codes and metrics. It encompasses aspirations for individual buildings, but also aspirations for transforming entire urban ecosystems in coupled social and biophysical terms. ${ }^{49}$

In the social sciences, urban ecology signals a vast, multidisciplinary body of work that might be clustered into many subgroups, just a few of which I detail here. In current anthropological work, particularly that which builds from anthropological strains of political ecology, efforts to theorize and analyze contemporary urban nature tend to follow longstanding theoretical discussions of "nature-cultures" and "socionature."50,51 Rather than enumerate an exhaustive list, it is useful to notice here two nodes of convergence between urban and environmental scholarly praxis that have generated new understandings of the dynamics that coproduce social and natural change..$^{22}$

The first node tends to locate its theoretical anchors in the Lefebvrian assertion that, by tracing the capitalist processes that knit together city and countryside, we are poised to recognize a "completely urban" world. ${ }^{53}$ From this vantage point, urban political ecology might be characterized by its primary attention to the multi-scaled conceptual and material systems that organize the flow of capital, labor, information, and power. These systems include cities, but are by no means confined to, or defined by them. Geographers have been particularly prolific in generating such mappings, while anthropologists and other ethnographers have demonstrated the historical and sociocultural particularities of larger scale processes when they are enacted in specific places..$^{54}$

A second cluster of contemporary social scholarship asks how the social analyses of the environment that developed in non-urban contexts might shed new light on our understanding of socionatural life in cities. Here, "urban" tends to signal cities and city life. While Lefebvre's broad urban processes are acknowledged, they do not automatically configure the field of inquiry. Field sites in this second group are usually located within or across specific cities or city neighborhoods, allowing researchers to explore how various forms of social asymmetry may be reproduced or reconfigured in the practice of urban environmental politics and management. By drawing from its legacy in environmental anthropology, this form of socioenvironmental inquiry affirms the fallacy of a clear rural-urban divide, but nevertheless takes the sociocultural and nonhuman natural life in dense human settlements to be distinctive from its non-city counterparts in significant ways. ${ }^{55}$

Both strains of scholarship emerged in response to three somewhat distinctive scholarly conversations in the social sciences, each a quest to rethink modern urban/rural and nature/culture binaries. One involved formally problematizing western analytical conceptualizations of ideal nature as located outside the city, and wholly separable from human culture; a second grappled with turn of the century globalism and economic globalization. ${ }^{56,57} \mathrm{~A}$ third group, galvanized primarily through work in geography, proposed analytics for studying the urban in a way 
that emphasized large-scale, interconnected nodes of power, and the material and social flows between them. Here the importance of movement and the notion of a simultaneously human and nonhuman "urban metabolism" formed an influential theoretical basis for specific research approaches. ${ }^{58}$

Among political ecologists in anthropology and sociology, Amita Baviskar's proposal of a cultural politics approach to natural resources, and urban applications of theoretical debates about attributions of agency to nature-such as those posed by Timothy Mitchell, Anna Tsing, and many others-challenged social analysts of all disciplines to confront the untenable essence of fixed nature/culture dualities.59,60 Among geographers, Castree and Braun's Social Nature laid useful groundwork for writing, as Braun encouraged elsewhere "a more than human urban geography." ${ }^{61}$ This, combined with sensitivities to the political dynamics of scientific knowledge and knowledge production-and particularly to "systems" thinking - set the stage for recent ethnographies of urban nature and urban sociality that defy easy disciplinary classification. ${ }^{62,63}$ Recent work by Timothy Choy exemplifies this new direction. ${ }^{64}$

The historian Dipesh Chakrabarty's previously mentioned, provocative call to rethink how scholars do their research in the Anthropocene Era brought the environment-its past, present, and possible futures-into sharp theoretical focus across the social sciences and humanities. ${ }^{65} \mathrm{~A}$ call for disciplinary scholars to reconsider the place of nonhuman nature and biophysical processes in all manner of inquiry, this work underlined the impossibility of responsible consideration of nature without social life, and vice versa. Studies of urban ecology, to this mode of thinking, automatically demand contextualized, ethnographic approaches to urban social and biophysical change. In outlining our analytical approach, $\mathrm{K}$. Sivaramakrishnan and I contend that these must remain interconnected with, and anchored to, historically produced social structures and imagined socionatural futures. ${ }^{66}$

But what is the relationship between analytical and theoretical approaches to urban ecology and an actual, lived life of environmental architecture? In this book, my dual focus on environmental architectural pedagogy and practice assembles an inquiry into the ways that urban ecology's prescriptives took social and material shape. I consider what conventional architects studied, and the extent to which they were able to do what they sought to do from their specific professional and historical positions in Mumbai. My goal was to observe whether and how ideas of what can and should be, according to the dictates of "good design," gave way to actual built forms. It is, after all, together that these comprise the material form of cities-precisely those things meant to be resilient and enduring in the biophysical and social fabric of a city.

A rich literature underlines the utility of distinguishing between architecture and design, as the historical, spatial, and political assumptions signaled by both are complex. ${ }^{67}$ In its very basic sense, architecture usually points to the making 
of individual structures, while design and its close associate, planning, signal the broader, specific, and desired interconnections between them. Keeping in mind their very distinctive, and quite consequential, histories, the reader will notice that in this work, I tend to use these terms interchangeably. This simply reflects their usage by the environmental architects with whom I worked and learned at RSIEA; but it should not be read as a dismissal of the very important theoretical insights that scholars of architectural history, postcolonial urbanism, and nationalist politics advance when they disentangle these processes carefully. ${ }^{68}$

In this work, the reader will notice the ubiquity of the term "good design," which RSIEA architects employed to mark an ecological rubric for how a built form should be conceptualized, sited, and interlinked with underlying water, energy, nutrient, and waste systems. Such contextualization gave singular built forms an assumed embeddedness in environmental processes at a variety of scales, including site-specific questions about orientation to light or shade, as well as questions of placement in a watershed or a mosaic of land use and land cover patches. In this sense, environmental architecture and "good design" were two expressions of a simultaneously singular and scaled undertaking, and green expertise was distinguished by the commitment to engage complexity through thought across multiple scales.

Thus the reader will also notice that the phrases "green architecture" and "green design" are also used interchangeably in this book; here again, I do not wish to imply an analytical conflation of architecture and design. I follow instead the terms that RSIEA architects used to index the wide array of technologies, materials, and conceptual approaches to building practices that they believed would improve the overall sustainability profile of a building and wider site, a city, and onward to an interconnected city-countryside continuum of urban landscapes.

Conceived in this way, we might consider the assumption of automatic embeddedness in broader environmental systems as a sustaining logic for linking "good design" to a transformative movement. That movement, in both global form and place-based expression, often explicitly aims to change core concepts, forms, and practices of ecology in and of cities.

As an ethnographer, I draw guidance in this book from the lived experience of contextualized, everyday life in a specific historical moment, and in the social processes through which people consciously described and experienced city space in the making. My hope is to explore the coupled social and biophysical choreography, however suspended it ultimately remained in the realm of aspiration, that brought urban ecosystem ecology into harmony with architecture, and ultimately with urban social forms. In doing so, I notice and mark points of friction, meaning-making, and experienced limits.

It is with care that I chose architects as the focal community for this work. Despite the compelling place of both the theoretical figure and the social agent, cultural anthropologists usually defer to the expertise of archaeology and scholarship in 
material culture to address the relationship between basic units of social organization and architectural forms, artifacts, and practices. Yet we have sometimes, intentionally or unintentionally, embraced rather rigid associations between built forms and social forms. In fact, the very endurance of architectural forms has sometimes led to fixed and determinative approaches to social explanation. ${ }^{69}$ In this study, imagining and making built forms are key social practices through which architects consciously and intentionally bridged their understanding of ecosystem ecology and their intentions for a more "sustainable" social reality in Mumbai.

Just as was true in earlier reference to the science-social science interface, the idea that material form and social life are interconnected is neither new nor novel. Among a host of examples in architecture and design history, the Green Cities Movement and related experiments in environmental design were in part intended to promote social vitality, and sometimes even social rehabilitation, by creating ecologically contextualized built forms. ${ }^{70}$ Likewise in this project, contemporary green architects often expressed intentions to promote or enable revitalized social configurations through their material designs. Unlike much modernist architecture, however, those intentions were grounded in an environmental restoration agenda animated by twenty-first century concerns over environmental change and the enduring postcolonial effects of deep socioeconomic disparities. In this context, the best designs would be responsive to biophysical uncertainties and sociopolitical imperatives, as well as to the conceptual values bundled in environmental architecture training as "good design," as I will show.

Focusing on the interface of material forms and social relations can sometimes seem to reduce urban and political change to technical questions, but my intention here is to do the opposite. The chapters to follow demonstrate the many ways that socially meaningful aspects of green design were in fact far more than technical, so much so that the most advanced technologies and materials often assumed a background position in pedagogical and praxis-based designations of "good design." In the foreground stood a more comprehensive moral ecology that enfolded core ideas about what was right and necessary for the good of society and the environment.

To appreciate this moral ecology fully depends on a careful treatment of the ways that architects cultivated and operationalized the specific hybrid knowledge form $^{71}$ they derived together in the context of training. That hybrid knowledge, which was used to characterize environmental architecture as an "integrated" subject, fused selected aspects of ecosystem ecology with equally selective design technologies and social objectives. It was that same hybrid knowledge form that distinguished the environmental architect from the architect, and in turn the green expert from the urban professional. ${ }^{72}$ Green expertise, however deferred in its actual practice, nurtured and reinforced a shared hope that Mumbai-and indeed, cities around the world — could be remade, and indeed could survive, in an increasingly uncertain environmental and social future. 


\section{A GLOBAL ENVIRONMENT IN AN URBAN CONTEXT}

Complex processes like urbanization, green design, and city life are often discussed as undifferentiated categories. Regarding them as universals, however, risks losing sight of a point advanced by Taylor and Buttel over two decades ago: that there are critical limitations to concepts, metrics, and simulations of environmental change conceived at the global scale when we seek to understand how actual change takes place in lived social life. ${ }^{73}$ Context, they argued, exerts profound, if highly differentiated, influence on how and when eco-social processes shift.

Across global discursive and policy discourses, green design circulates with prominence and purchase. It is often invoked to provide alternative trajectories for housing and infrastructure development, energy regimes, and resilience planning. Yet our understanding of the social and political dynamics of green design in specific contexts is curiously limited. At best, we have only a preliminary understanding of the cultural and historical narratives from which green design derives its place-specific legitimacy, force, and moral authority. This book aims to more clearly define the contextualized social, political, and cultural processes through which green design knowledge circulates, transforms, and is operationalizedeven if only in aspiration. By attending to these factors, we are better positioned to understand the structural barriers that prevent city-scale ecological change, and to calibrate initiatives to change the actual barriers they encounter. At the same time, we stand to gain a more sophisticated appreciation of the importance of sustained aspiration among those who stand trained and poised to implement specific kinds of ecological practices.

The potential impact of green design technologies and practices is obviously far-reaching. It is imperative, then, that we understand the particular fusions of scientific and social scientific knowledge that constitute their basis, and the moral ecologies, temporal sensibilities, and ecologies in practice that characterize their contextual variability. Clearly new relationships to the environment are being forged through the practice of green design; so, too, are new social relationships and wholly new political ecologies of cities and non-city spaces.

Toward that end, over fourteen cumulative months between 2007 and 2012 (including a period of eight continuous months in 2012) I used mixed social research methods to understand the social life of green architecture in Mumbai. I employed participant observation at RSIEA, in its Master of Environmental Architecture classes, and on the educational field trips that are part of the Institute's curriculum. I undertook additional participant observation among Institute faculty members, and among students who had completed the program and gone on to work in Mumbai as certified environmental architects.

To trace students' post-program experiences, I administered surveys to all RSIEA students, then-present and past. Of one hundred and five total graduates at the time of the research, I was able to survey ninety-six. Additional archival 
materials provided information on the historical context for environmental design in Mumbai, as well as its contemporary life as a pedagogical undertaking and a mode of professional practice. Finally, through a separate interview protocol, I administered twenty-seven semi-structured interviews and focus groups with students, and seven interviews among other relevant practitioners. Eight additional interviews were conducted with active RSIEA faculty members.

As a center for dynamic design in India, Mumbai hosts many environmental architecture training programs and professional groups. Several are better known, and by far more elite, than Rachana Sansad. While I learned a great deal about other programs, and met many people active in other arenas of environmental architecture practice and pedagogy, I focused my fieldwork specifically on RSIEA. This allowed me to concentrate my inquiry on a specific subset of Mumbai's architects who are committed to environmental design; it also enabled a richer contextual sense of the camaraderie that developed between these specific professionals who, once they graduated, continued to draw from their common experience of training and practice. A focus on RSIEA also allowed me to more fully experience, and therefore better understand, the academic curriculum through which ecosystem ecology was conveyed as, and then transformed into, design practice.

It is important to note that, although today RSIEA stands among many similar postgraduate programs in Mumbai, the Institute for Environmental Architecture was the first and only program of its kind in India when it was inaugurated in 2002. It was Roshni Udyavar Yehuda, the Program Head throughout this study, who authored the pioneering curriculum, and who has since watched it flourish alongside many others in the city.

Caste and class dimensions, ethnic and religious diversity, geographic mobility, and linguistic capacity also distinguished the group of architects I profile in this book. In contrast to more elite architecture programs in Mumbai, RSIEA is not generally considered the pinnacle of architectural study, either internationally or in India. It boasts successful graduates, but it is not generally associated with prestigious international firms or elite national and global connections. Indeed, those students from privileged and wealthier backgrounds, or with more international educational experience, tend to enroll and participate in other programs in Mumbai's vast architecture and design community. Focusing on RSIEA offers particular insight into the experience of Greater Mumbai-based, middle and lowermiddle class professionals who were likely to remain in Greater Mumbai and Maharashtra after their training was complete. I use "middle and lower-middle class professionals" as a heuristic rather than a clear and constant category here, however, since the architects I learned among were nevertheless quite removed from the more glamorous and often transnational world of architectural elitism. Most came from Greater Mumbai, and remained in Maharashtra as practitioners after they completed their master's degree. They assembled from extremely diverse caste, religious, linguistic, and geographic backgrounds, but all had achieved 
fluency in English sufficient to train and earn their degree in that language. All had the capacity and willingness to enroll in a highly diverse, cosmopolitan setting for this training. Many took out formal loans to cover the costs associated with RSIEA, so they were also sufficiently socially positioned to gain access to formalized structures of credit and debt. In general terms, we may think of the architecture students at RSIEA as a set of bourgeois middle class professionals. Although not from the furthest class and environmental margins of the cityas was the case in my previous studies in Kathmandu-students at RSIEA each espoused specific caste, class, gender, and other conditions that influenced, in part, how and where their aspirations to make fundamental social and environmental change would be realized, and how and where they would face obstacles. As social actors, RSIEA architects were beholden to myriad established relations of power, constraints to mobility, and, in this specific instance, education or other forms of life-structuring debt. Despite their differences, as I will show, they cultivated what I have called elsewhere an environmental affinity group that allows us to consider them together, and to examine the moral ecological logics they assembled as they shared a commitment to "good design." ${ }^{4}$

The ethnography and analysis to follow are shaped by a set of core research questions. Each derives from a central and enduring interest in the ways that concepts of nature transform, and how that transformation relates to social and political life. I ask, how is the environment made, and made meaningful, in urban settings?

To ask how the environment is made is to highlight how the pedagogy of environmental design - the selection of historical narratives, notions of social duty and responsibility, aspects of ecosystem ecology that were conveyed and taught, and modes of transforming them into essential design techniques and skills-actually constituted a built form bridge between "more than human" nature and morethan-technical environmental design. ${ }^{75}$ Understanding the form and content of that bridge is essential if we are to understand the origins of formal diagnoses of urban environmental problems.

Likewise, to ask how the environment is made meaningful is to recognize that human social action is always predicated on the making of shared values and meaning systems. Values and meanings are in turn often associated with particular visions of, and fears about, the present and likely future. Arjun Appadurai has noted that green design has a specific discursive quality that tends to bring the future into the present; this book explores how that consciousness of present and future made processes of identity formation (the we of the collective), narrations of history (in this case, defining Indian green architecture), and challenging or claiming the place of Mumbai on a map of cities that achieve prominence on the global stage, were all important avenues for attributing meaning to environmental architecture and the work of the architect. ${ }^{76}$ 
We have already seen how the environmental architect can be constructed as the vanguard of a social movement, a special subforce in service of changemaking in Mumbai. It is important to ask further, how did that vanguard define meaningful urban nature, and how did it seek to enact it through material practices? What moral ecologies and temporal sensibilities compelled them? For scholars interested in urban environmental change, there is perhaps no more fruitful place for answering these questions than among the architects themselves as they learned, debated, and sought to practice green design.

I assume in this work that architecture is a field of cultural production in Bourdieu's sense; there is no single and stable voice of all architects, but there are nevertheless important agents and institutions. In the present case, this would include, among many others, the All India Council for Technical Education, which was reformed in 2009, the Council of Architecture, the RSIEA-accreditor Yashwantrao Chavan Maharashtra Open University, and even the Archaeological Survey of India. ${ }^{77,78}$ The actions of these institutions simultaneously produce specific cultural goods (in this case often by guiding and certifying a curricular structure) and those interested in, and positioned to, consume them. Many other relevant agents and institutions also exist, and exercise influence, at a variety of scales, from the global (such as the internationally recognized BREEAM metrics or LEED standards) to the regional (such as GRIHA). ${ }^{79,80,81}$ Although regularly contested, these institutions and agents were also regularly invoked as sources of legitimacy, and so produced and reproduced the templates for specific kinds of built forms, and those who sought to consume the attributes of those forms.

In the next chapter, I set out to understand the social life and practice of environmental architecture at Rachana Sansad Insitute for Environmental Architecture, first through the genesis narratives and curricular goals espoused by founding faculty members in the Institute, and then by noting the profound-almost unbelievable-sense of optimism and possibility that formed their basis. The study continues to explore how "good design," a quality foundational to the RSIEA curricular mission and yet very diffuse, was conceived and conveyed. These opening sections trace social and pedagogical life at RSIEA through an entire curricular cycle, following students on mandatory field trips, accompanying them in the classroom and in project work, and describing the gradual formation of alliances and affinities that would extend far beyond the two-year master's program. They show how basic conservation biology and systems science principles formed the scientific basis for green architectural pedagogy, while specific narrations of history, vernacular tradition, and climatic specificity attached the science to locally grounded techniques and practices.

Chapter 3 begins by describing the opening session of Rachana Sansad's 2012 Environmental Architecture course, which featured a collective screening of the American climate change film An Inconvenient Truth. It examines the distinctive 
blend of globally and locally circulating technical material that was hybridized to produce and convey a Mumbai- and India-specific concept of good design.

By this point, the reader will find the broader context of the city noticeably absent, and so two chapters follow that refocus our attention on the broader urban and temporal contexts in which RSIEA architects trained. In these chapters live debates about greening the city and contrasting public exhibitions calling for new urban plans and designs sharpen our view of the public spectacles that characterized contests over Mumbai's urban form and future.

These chapters also reposition our attention onto the concept of open space, an omnipresent, quite popular, and yet deeply problematic prescriptive in this period. Departing for a moment from my direct attention to RSIEA in order to follow one of its faculty members to an important urban forest patch, I trace the politics of exclusion embedded in aspirations and practices of good design.

Fortified with an ethnographic snapshot of RSIEA and a sense of the urban context that enfolded it, Chapter 6 then follows RSIEA students through a key aspect of RSIEA pedagogy: their ventures outside the city. Centrally important field trips, like the BCIL journey I described in the opening pages of the book, played an important role in synthesizing the idea of a distinctly Indian history, quality, and imperative for good design. This section considers some of the sites, their complex histories and symbolics, and the ways that encounters there were structured and limited by environmental pedagogy. This chapter shows that regardless of the presumptive power of sustainability to render such places instantly neutral, producing green expertise was a history-claiming endeavor that depended on a culturally grounded spatial geography to enchant and make meaningful a more globally legible choreography of technical training and skills.

From the training journeys far afield, Chapter 7 returns to Mumbai to trace how good design aspirations fared in domains of practice. The reader follows RSIEA graduates, and students on the cusp of graduation, as they seek to turn environmental architecture into ecology in practice. Interviews with a range of graduates bring the core tensions between the structural forces of urbanization and the aspirations of RSIEA's green architects to life as we encounter the complex of power relations and bureaucratic structures that modify grand plans. We also trace the resilience of the moral ecologies and temporal sensibilities that maintain green design as a tool of future salvage and a marker of identity. While the structural elements of economic growth, new building construction, and socioeconomic development in Mumbai constitute several books in their own right, this chapter sketches their formative contours by noting how they converge with green architects' agentive efforts.

The contextualized, structurally conditioned figure of the architect returns in the book's conclusion; so too does the importance of moral ecologies and temporal sensibilities for making dormant aspirations into resilient forces shaping social 
life, social change, and ecologies of urbanism in Mumbai. Indeed, whether studying social change or ecological process or both, our tools of analysis are in a flux that mirrors the lived realities profiled, and suspended in layers of context and power, in this book. 